\title{
A Cooks Distance Approach to Control the Haz and Arc Length of Tig Mild Steel Weld
}

\author{
F. O. Uwoghiren and A. Ozigagun
}

\begin{abstract}
The heat affected zone and arc length parameters have a vital role to play in determining the integrity of a weld structure. The cooks distance is a statistical diagnostic employed in this study to select the best optimum combination of welding process parameters. Mild steel plate was the choice material used to produce the weld specimen, which was welded with the Tungsten inert gas method. The RSM model was used to develop an optimal solution that can explain the behavior of the welded joint with respect to the heat affected zone and arc length, different diagnostic techniques were employed which includes the normal probability plot and cooks distance plot. The model developed has sufficient merit as the results obtained shows that the cooks distance values is within the range of 0 and 1 indicating the absence of outlier in the data making the optimal solution highly acceptable.
\end{abstract}

Index Terms - Arc length, cooks distance, control, heat affected zone, inert gas, mild steel, weld, Tungsten.

\section{INTRODUCTION}

Tungsten inert gas welding (TIG) popularly known for its production of excellent quality welds having minimum fumes, slags and porosity [1].

Gas tungsten arc welding process is applicable to different steel materials; most metal fabrication workers prefer this technique because of its cost effectiveness [2].

During welding the solid metal is transformed into a molten state by the application of heat, which cools off and solidifies. The process of heating, cooling and solidification determines the quality of the weld bead geometry.

It is well known that the heat generated in a welding process is the product of the voltage and current. To get the most suitable heat input that will melt the solid metal and filler wire effectively, then the technique of optimization is required to select and control the welding process parameters [3]. Having knowledge of the arc length and heat affected zone of the welding process and combining these parameters optimally can be used to produce very reliable numerical models to help predict the output quality of mild steel fabricated structures. The correct determination of these factors significantly influences the quality and

\footnotetext{
Submitted on July 28, 2021.

Published on August 20, 2021.

F. O. Uwoghiren, Department of production Engineering, Faculty of Engineering, University of Benin, P.M.B 1154, Benin City, Edo State, Nigeria.

(e-mail: frank.uwoghiren ${ }^{\circledR}$ yahoo.com)

A. Ozigagun, Department of production Engineering, Faculty of Engineering, University of Benin, P.M.B 1154, Benin City, Edo State, Nigeria.

(e-mail: andrewzigs@yahoo.com)
}

properties of the finished products [4]. An increase in productivity is the desire of every industrial or manufacturing organization and this can be achieved by integrating a robust optimization technique [5]. Optimization processes today have integrated some statistical techniques to increase the reliability of the optimal solution, the cooks distance is one of the statistical diagnostics employed. Cook's Distance is a statistical tool used to check for errors present in a given experimental data. In developing a regression model ,the data has to be free from outliers known as erroneous data, the presence of outliers has an influence on the accuracy and reliability of the model [6].The kernel density estimation is nonparametric technique required for data smoothening which behaves similar to the cooks distance [7], and later suggested a type of Cook's distance in local polynomial regression [8].The exact distribution of Cook's distance was used to estimate the error found in a multivariate regression analysis. The authors revealed the resultant density function of the cook's distance calculated the acute points of Cook's distance at $5 \%$ and $1 \%$ confidence levels. The results obtained was compared to the traditional rule of thumb technique which shows better scientific and systematic properties [9].

\section{RESEARCH METHODOLOGY}

In this section, the materials and response surface methodology and the TIG welding process is described and explained. Furthermore, the RSM diagnostics and cooks distance results are explained and interpreted. In this study an optimum experimentation to control the heat affected zone and arc length was performed. An appropriate design of experiment was generated using the design expert software. The material used to produce the experimental specimen was mild steel and weld joints were formed using the TIG welding process.

\section{A. Material Selection}

The choice of material selected for this study was mild steel, it was choosen because of its availability. This grade has high corrosion resistance and can be operated at elevated temperatures, the Tungsten inert gas welding technique was selected because of its fine weld product quality. A matching filler wire having similar property of the base metal was selected. The need to protect the weld pool from environmental gaseous interference, a shielding gas such as Argon, Helium, or carbon dioxide is required.

\section{B. Welding Process Parameters}

The welding process parameters consists of current, voltage, gas flow rate, their range of values are shown in 
Table I.

TABLE I: INPUT FACTORS

\begin{tabular}{ccccc}
\hline Parameters & Unit & Symbol & Lower level & Higher level \\
\hline Current & Ampere & I & 119 & 170 \\
Voltage & Volts & V & 20 & 24 \\
speed & $\mathrm{m} / \mathrm{min}$ & $\mathrm{W}$ & 0.2 & 0.5 \\
\hline
\end{tabular}

\section{Experimental Procedure}

Weld samples were produced using a $10 \mathrm{~mm}$ thick mild steel plate. For the welding current varying from 119 to 170 amps, welding speed 0.2 to $0.5 \mathrm{~m} / \mathrm{min}$ and voltage 16 to 22 volts .In the present work, mild steel plates of $10 \mathrm{~mm}$ thickness and $60 \mathrm{~mm}$ lengths were butt joined using the desired filler rod at varying levels of current voltage and gas flow rate $\mathrm{t}$ by manual TIG welding process. These three parameters were taken as variable for present study and their three levels were chosen for which responses were measured, and the central composite design was selected as the experimental design method. These parameters with their levels are shown in Plate 1. The experimental data for the heat affected zone and arc length is presented on Plate 1.

\section{RESUlTS AND DisCUSSION}

To check for outliers and difference in fits in the values of the arc length, a comparison is done between the observed and predicted values which is shown on Plate 2.

A comparison between the predicted and observed values of heat affected zone was presented, to help check for the presence of outliers as shown in Plate 3.

To check for the suitability and acceptability of a model, a plot of residuals is needed to check for normality distribution along the 45 degree line, the normal plot of residual for heat affected zone (HAZ) response is shown in Fig. 1.

To ascertain the suitability of the second order polynomial model for the arc length data, a normality plot is required to check for a straight-line cluster or a scatter. The normality plot of residual for arc length is shown in Fig. 2.

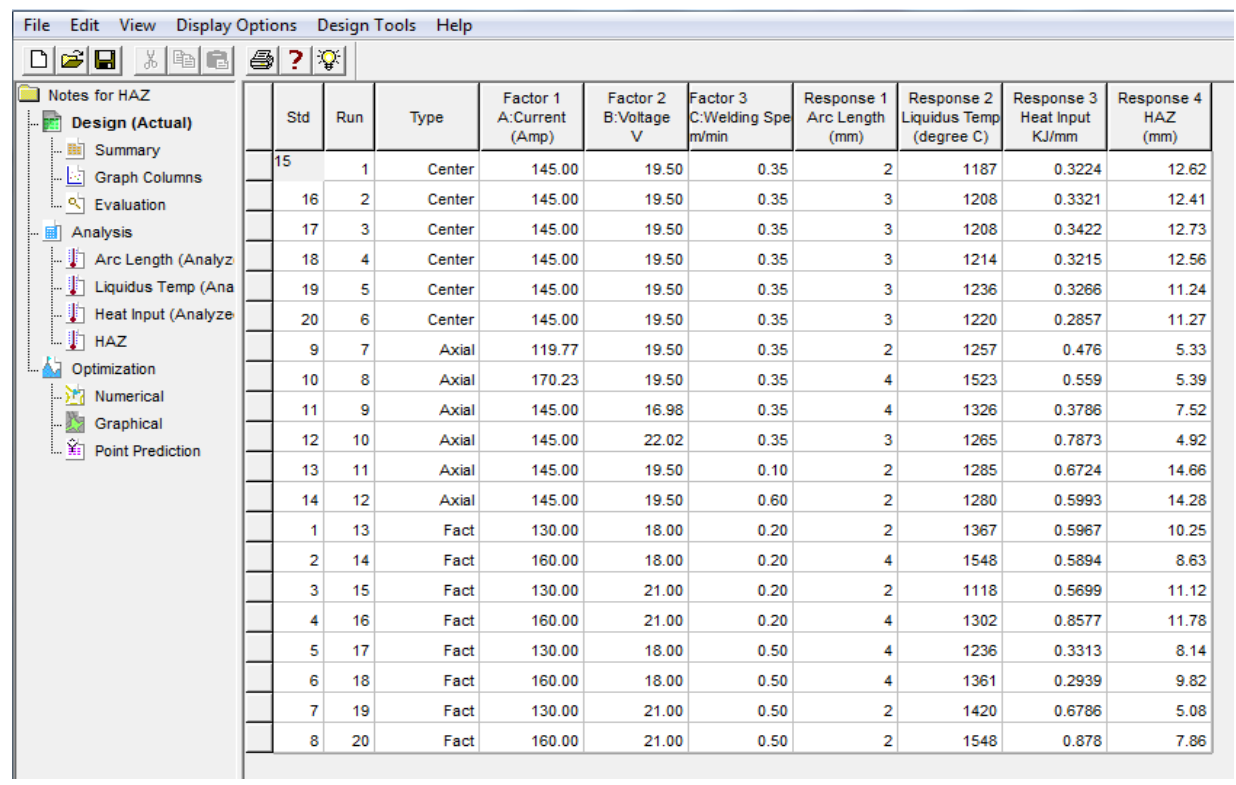

Plate 1. Experimental data.

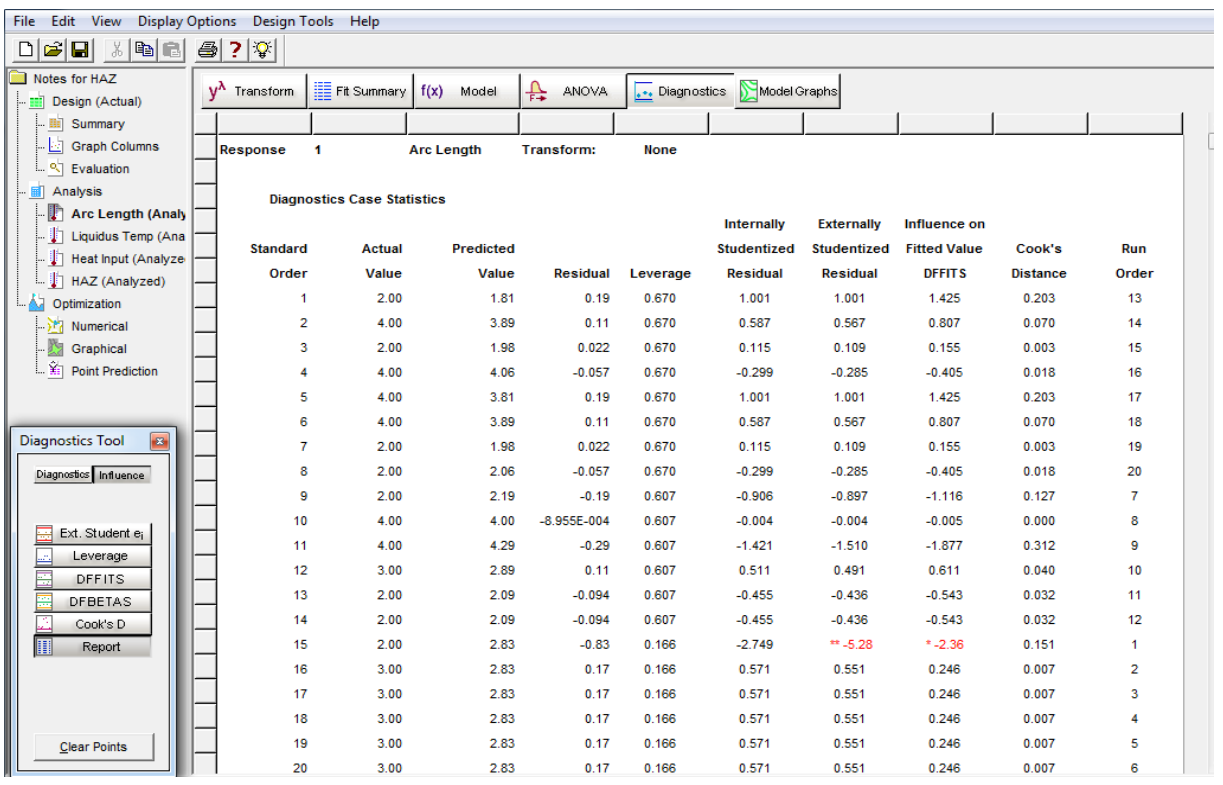

Plate 2. A comparison between observed and predicted values arc length. 


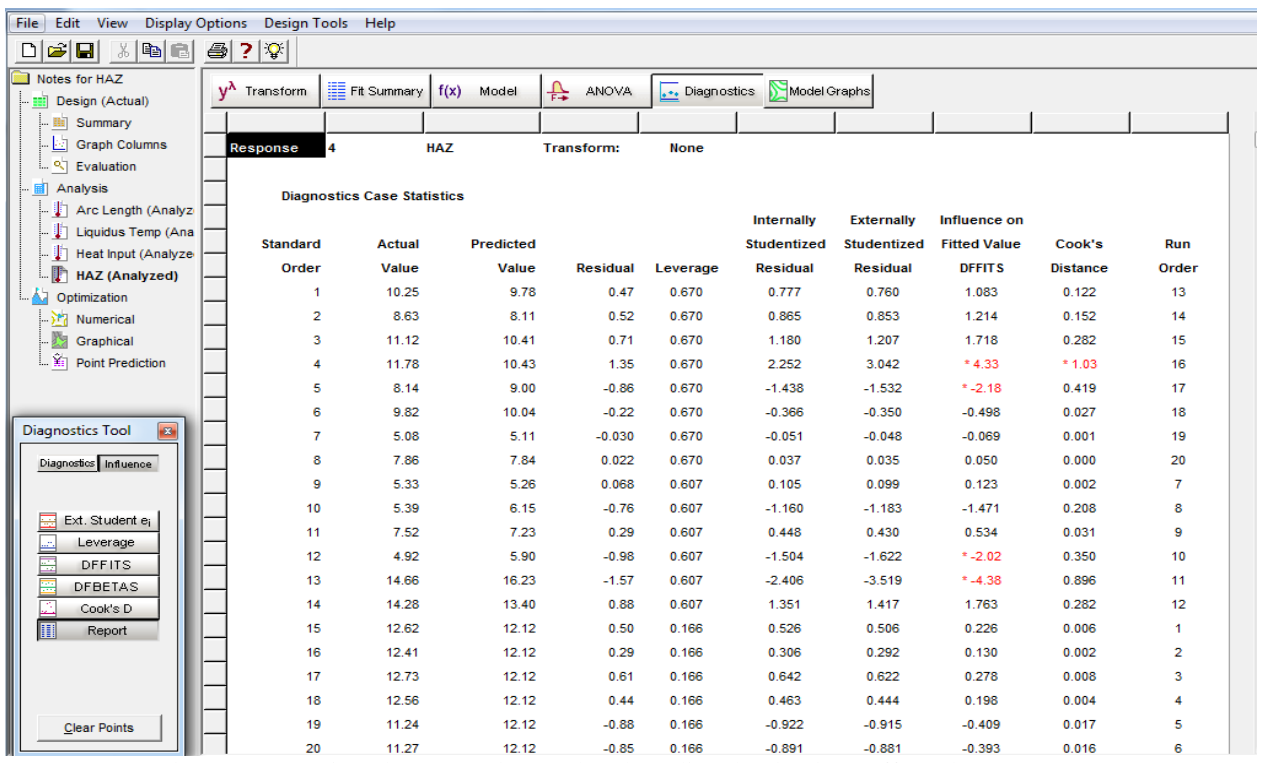

Plate 3: comparison between observed and predicted value heat affected zone (HAZ).

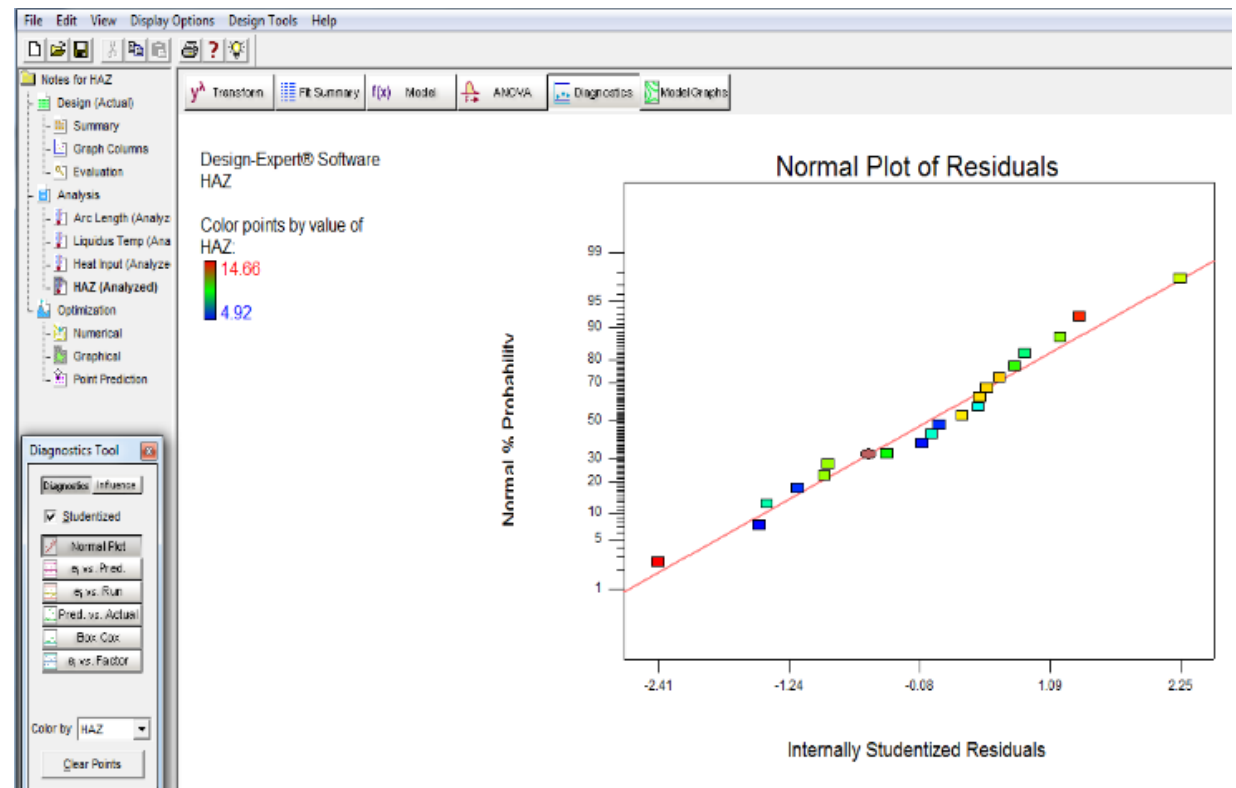

Fig. 1. Normality plot of residuals for heat affected zone.

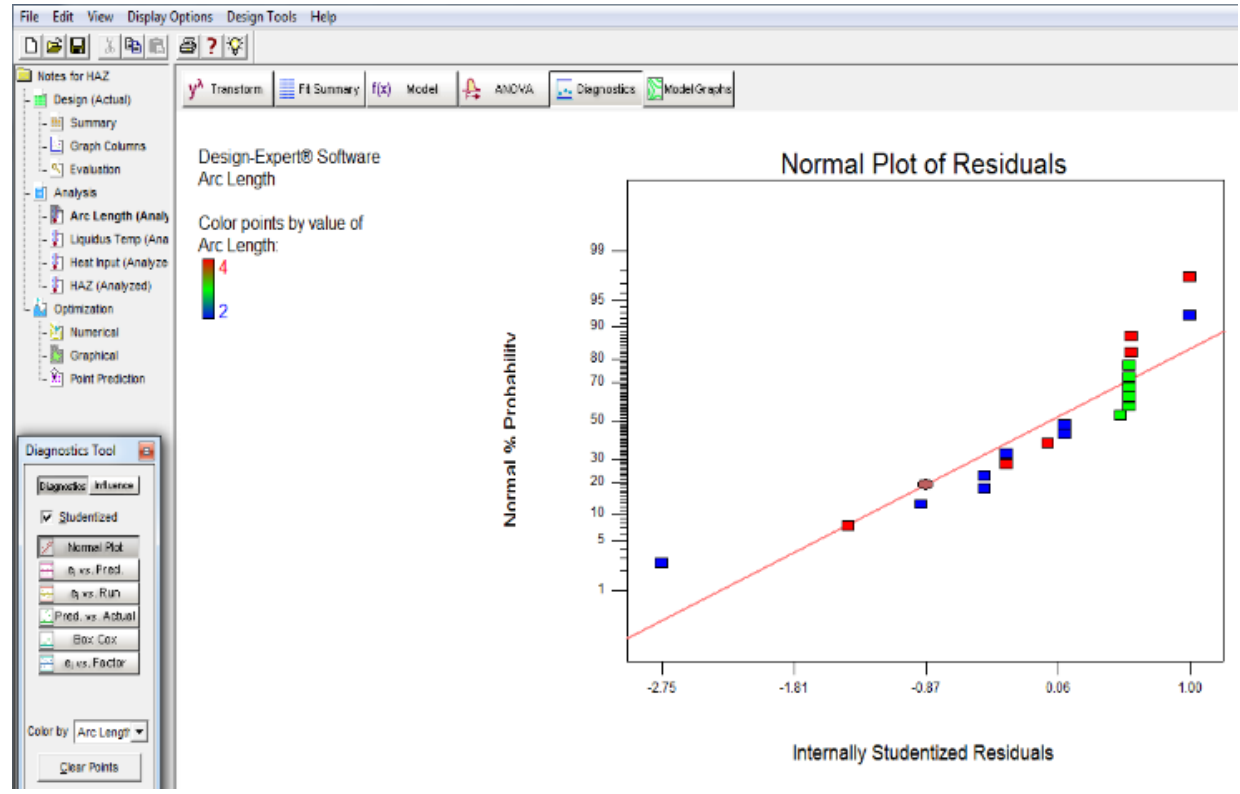

Fig. 2. Normality plot of residuals for arc length. 
The cooks distance is a support diagnostics which validates the second order quadratic model. it helps to expose any outlier present in the data. The cook's distance plot for arc length is presented in Fig. 3.

To determine the accuracy of the data collected, a cook's distance plot is required to expose any outlier. The cook's distance plot for heat affected zone is shown in Fig. 4.
To evaluate the accuracy and reliability of prediction capacity of the second order quadratic model a reliability plot was produced for heat affected zone as shown in Fig. 5.

To evaluate the reliability of the predictive capacity of the second order polynomial a reliability plot was produced for arc length as shown in Fig. 6.

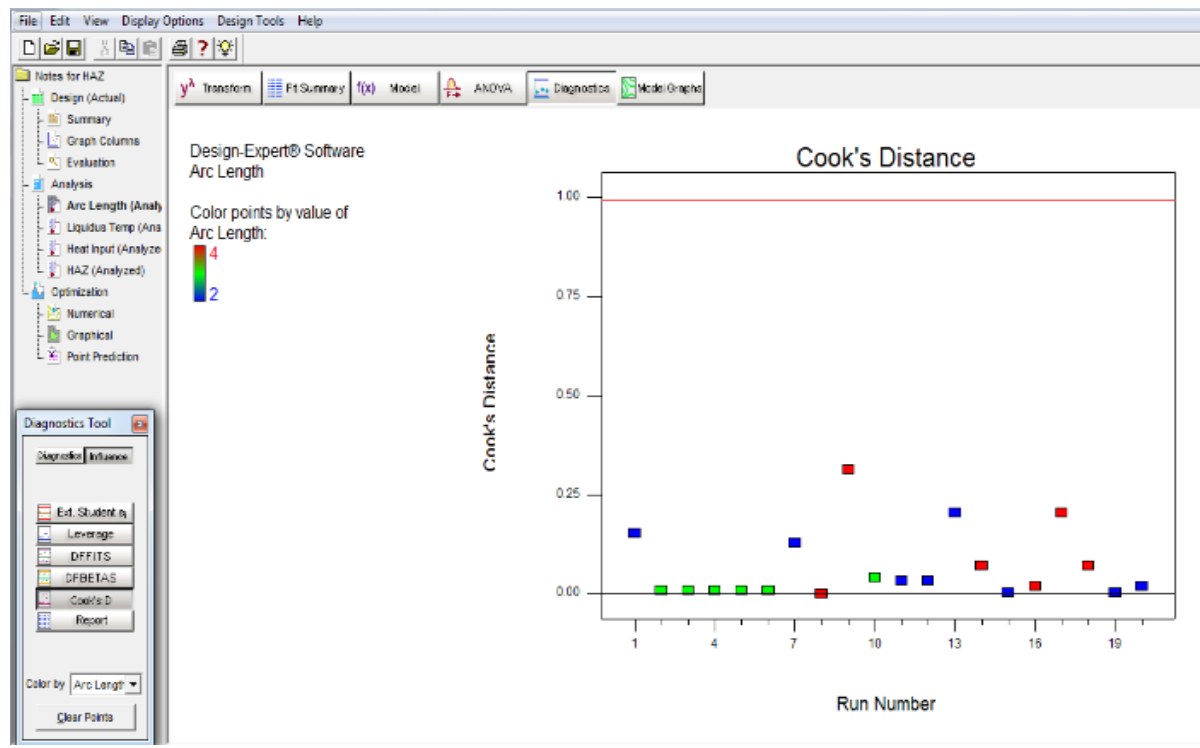

Fig. 3. Generated cook's distance for minimizing arc length.

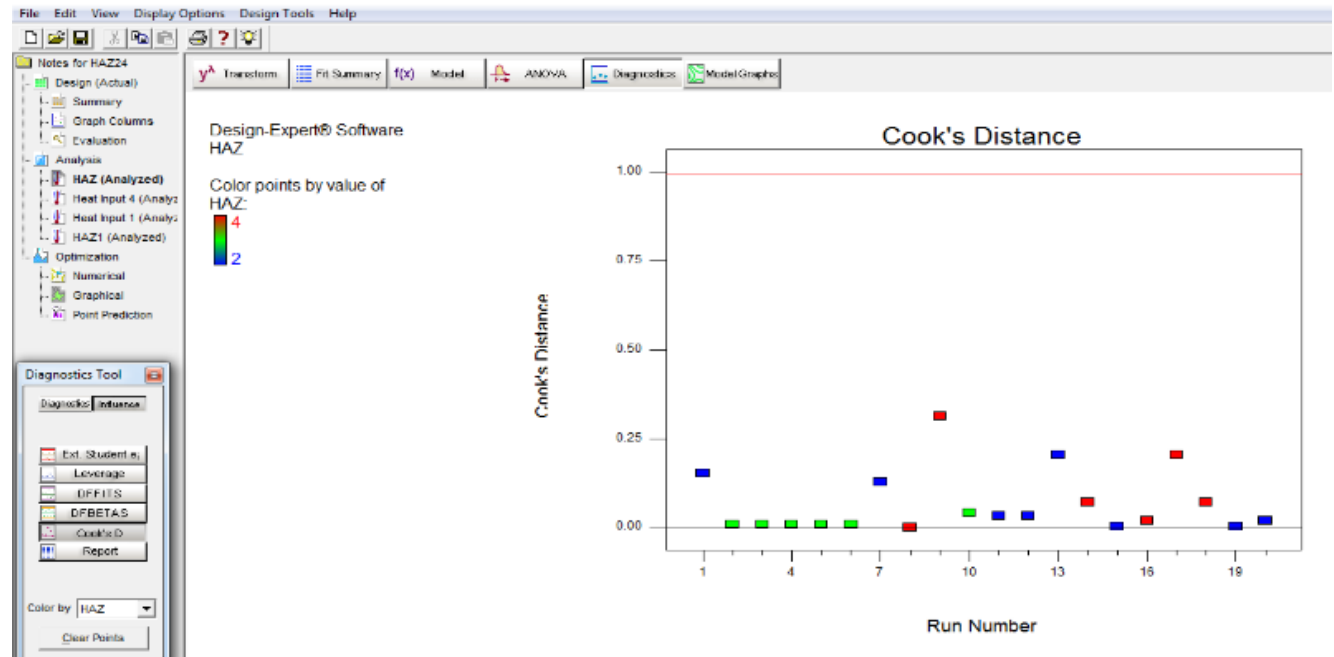

Fig. 4. Cook's distance plot for heat affected zone.

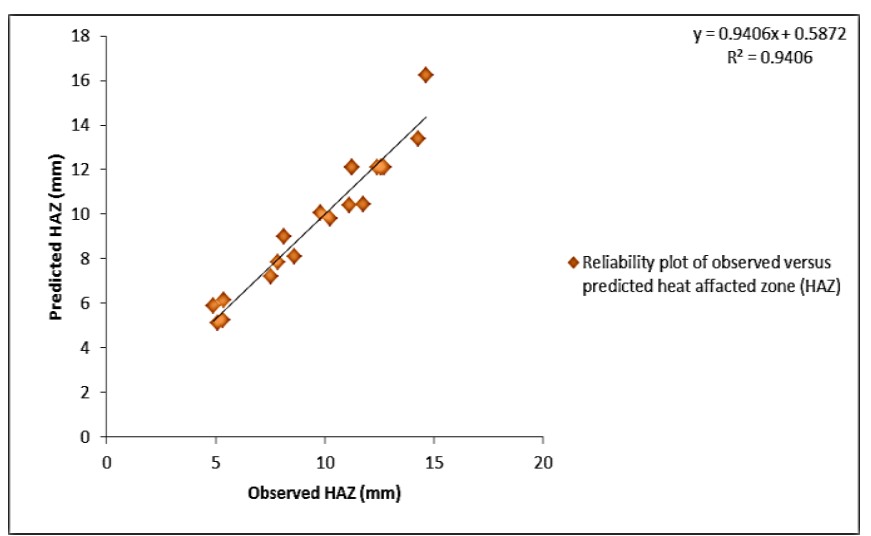

Fig. 5. Reliability plot for heat affected zone.

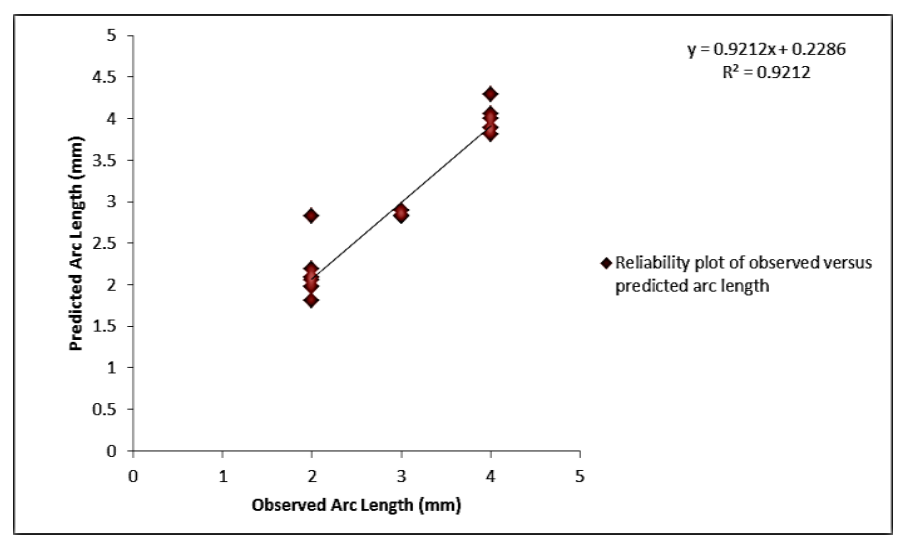

Fig. 6. Reliability plot for arc length. 
TABLE II: NUMERICAL OPTIMAL SOLUTIONS

\begin{tabular}{ccccccc}
\hline Number & current & Voltage & $\begin{array}{c}\text { Welding } \\
\text { speed }\end{array}$ & Arc length & $\begin{array}{c}\text { Heat affected } \\
\text { zone }\end{array}$ & Desirability \\
\hline 1 & 130 & 20.94 & 0.48 & 2.044 & 5.42 & 0.962 \\
2 & 130 & 20.96 & 0.49 & 2.045 & 5.37 & 0.962 \\
3 & 130 & 20.91 & 0.49 & 2.042 & 5.51 & 0.962 \\
4 & 130 & 20.91 & 0.48 & 2.039 & 5.51 & 0.962 \\
5 & 130 & 20.97 & 0.49 & 2.045 & 5.32 & 0.962 \\
6 & 130 & 20.92 & 0.49 & 2.032 & 5.46 & 0.962 \\
7 & 130 & 20.90 & 0.49 & 2.030 & 5.54 & 0.962 \\
8 & 130 & 20.86 & 0.50 & 2.036 & 5.67 & 0.962 \\
\hline
\end{tabular}

\section{A. Discussion}

The second order quadratic model was selected as the best model that can accurately optimize the HAZ and arc length of TIG welding process; The diagnostics case statistics which shows the observed values of the two responses against their predicted as presented in Plates 2 and 3. The diagnostic case statistics helps us to look out for data obtained in error and compare the value of the predicted against the value of the observed.

To validate the selection of the quadratic model as most suitable for the HAZ and the arc length data a cook's distance plot was produced as statistical diagnostics to support our decision. Cook's distance helps us to check for the effect an outlier will have on the regression equation if omitted.

The model developed has sufficient merit to control the heat affected zone and arc length optimally.

\section{CONCLUSION}

This study was carried out to develop models to optimize the heat affected zone and arc length of welded joints using TIG welding process. The RSM technique was employed to develop the models and the cooks distance was used to measure the integrity and reliability of the model. The diagnostic case statistics showed the residuals, predicted, actual and the cooks distance values for the heat affected zone and arc length model. The cooks distance falls within the range of 0 and 1 indicating that there is no outlier in the data making the optimal solution acceptable.

\section{REFERENCES}

[1] Vijay, G., Jatin, M. and Riteshkumar, R., "Optimization of process parameter for tensile strength and hardness of S.S 304 by TIG welding," International journal of engineering development and research (IJEDR), 2016, vol. 4, issue 2. pp. 756 .

[2] Dongjie L, Shanping L, Wenchao D, Dianzhiong L, Yiyi L., "Study of the law between the weld pool shape variations with the welding parameters under two TIG processes," Journal of Materials Processing Technology, 2012, vol. 212, pp. 128-136.

[3] Jung S.C, and Trang Y.S., "Process Parameters Selection for Optimizing the Weld Pool Geometry in the Tungsten Inert Gas Welding of stainless Steel," Journal of Materials Processing Technology, 2002, vol. 122, pp. 33-37.

[4] Khosravifard A, Hematiyan M.R and Wrobel L.C, "Simultaneous control of solidus and liquidus lines in alloy solidification," Engineering Analysis. Boundary of Elements, 2013, issue 34, pp. 211-224.

[5] 5 Rama, K.V, Harinadh V and Murthy K.L.N., "Optimization of TIG Welding Parameters on SS Materials using Regression Analysis," IJSRD National Conference on Recent Trends and Innovations in Mechanical Engineering, 2016, issue 14, pp. 75-78.

[6] Kim, C, "Cook's distance in spline smoothening," Statistics and Probability Letters, 1996, vol. 31, issue 2, pp. 139-144.

[7] Kim,C and Kim W, "Some diagnostics results in nonparametric density estimation," Common Statistical Theory Methods, 1998, vol. 27, pp. 291-303.

[8] Kim, C Lee, Y Park, B.U, "Cook's distance in local polynomial regression," Statistical Probability Letter, 2001, 54, pp. 33-40.

[9] David G.S, Jayakumar S. and Sulthan, "Exact distribution of Cook's distance and identification of influential observations, "Journal of Mathematics and Statistics, 2015, vol. 44, issue (1), pp. 165-178. 